\title{
Bacteriocin diversity and the frequency of multiple bacteriocin production in Escherichia coli
}

\author{
Correspondence \\ David M. Gordon \\ David.Gordon@anu.edu.au
}

Received 17 November 2005

Revised 30 June 2006

Accepted 1 August 2006

\section{David M. Gordon and Claire L. O'Brien}

\author{
School of Botany and Zoology, The Australian National University, Canberra, ACT 0200, \\ Australia
}

\begin{abstract}
A collection of 266 faecal isolates of Escherichia coli from humans was assayed for the production of mitomycin C-inducible bacteriocins and screened using a PCR-based method for the presence of eleven colicins and seven microcins. Eight different colicins were detected and all seven microcins. Of the strains examined, $38 \%$ produced a bacteriocin, $24 \%$ produced a colicin and $20 \%$ produced a microcin. Of the 102 bacteriocin-producing strains, $42 \%$ produced one type of bacteriocin, $41 \%$ produced two, $16 \%$ produced three and one strain was found to produce four different bacteriocins. Strains producing more than one bacteriocin were more likely to be members of $E$. coli genetic group B2 and less likely to belong to genetic groups A or D. Several of the bacteriocins were found to co-occur in a strain more often than would be expected by chance: microcins $\mathrm{H} 47$ and $\mathrm{M}$; colicin la and microcin V; colicins $\mathrm{B}$ and $\mathrm{M}$; colicins $\mathrm{E} 1$ and $\mathrm{M}$; colicins $\mathrm{E} 1$ and la. No bacteriocins released as a consequence of cell lysis were found to co-associate more often than expected by chance. Three non-mutually exclusive hypotheses are presented that might explain the high frequency of multiple bacteriocin production in E. coli strains: (1) expanded killing range, (2) expanded receptor repertoire and (3) fitness benefits in different environments.
\end{abstract}

\section{INTRODUCTION}

Allelopathy is the production of chemical compounds that are toxic to other organisms but not to the producers of these compounds. For micro-organisms there is a wealth of data demonstrating that allelopathy is an important mediator of intra- and interspecific interactions and, consequently, a significant factor in maintaining microbial biodiversity (Czaran et al., 2002; Kerr et al., 2002). In bacteria, these allelopathic substances include metabolic byproducts such as ammonia or hydrogen peroxide, the 'classical' antibiotics such as bacitracin and polymyxin B, lysozyme-like bacteriolytic enzymes and the protein antibiotics known as bacteriocins. Bacteriocins are the subject of increasing attention as potential replacements for traditional antibiotics and as natural food preservatives (Gillor et al., 2004). In addition, bacteriocin production is considered to be a key trait of strains used in probiotic formulations employed to prevent the establishment of microbial intestinal pathogens (Center for Veterinary Medicine, 1997).

Escherichia coli is known to produce two types of bacteriocins. One class, colicins, are diverse. This diversity and the evolutionary forces creating it are well known, as are the molecular and biochemical characteristics of these compounds (Riley \& Wertz, 2002). Colicin proteins are

A table of primers is available as supplementary data with the online version of this paper. produced in a cell following stress (SOS response). The colicin gene cluster is plasmid-encoded and always consists of two tightly linked genes: a gene that encodes the toxin, and a constitutively expressed immunity gene, whose product protects the cell from the colicin. Many colicin determinants also encode a stress-induced lysis protein. This protein ruptures the cell, releasing the colicin into the environment. If a lysis protein is not produced, the colicin is actively transported across the cell membrane into the external environment. Once released, colicin molecules bind to specific cell surface receptors on target bacteria, from which they are transported into the cell. Colicins typically exploit receptors involved in nutrient uptake, such as vitamin B12. Once the colicin has entered the target cell it will, depending on the type of colicin, kill the cell in one of three ways: by forming channels in the cytoplasmic membrane, by non-specific DNA degradation, or by inhibiting protein synthesis.

The second class of bacteriocins produced by E. coli, the microcins, are less well understood (Braun et al., 2002). The gene cluster may be chromosomally or plasmid encoded and comprises two genes: the microcin gene, which encodes the bactericidal protein, and the immunity gene. Cells are induced to produce the microcin protein under specific conditions, such as iron limitation. The release of microcins is not a consequence of cell lysis; rather, the microcin is actively secreted from the cell. The export of microcins can be complex and often involves microcin-specific proteins as well as basic 'housekeeping' proteins. Most microcins are 
thought to bind to surface receptors on target cells involved in iron uptake. The manner in which microcins kill cells is not generally known, but some disrupt the target cell's membrane potential.

For those colicins released via cell lysis, there is a wealth of mathematical theory (Levin, 1988; Frank, 1994; Durrett \& Levin, 1997), as well as in vitro (Chao \& Levin, 1981; Gordon \& Riley, 1999; Kerr et al., 2002) and in vivo (Kirkup \& Riley, 2004) experimental evidence, that demonstrates the potential importance of colicins in mediating intraspecific interactions and their highly dynamic nature. However, our current understanding of the dynamics of bacteriocin production is not only restricted to those colicins released via cell lysis, but has only considered populations consisting of a single type of producer. Recently developed mathematical models predict that, under some circumstances, most strains of a bacterial community will evolve to produce multiple bacteriocin types (Czaran et al., 2002). To understand the potential benefit arising from the production of multiple colicin types, consider a community initially consisting of a sensitive cell population and two populations of producing cells, each encoding a single colicin type. If one of the producing cells acquires, through recombination, the genes for the other colicin type, then this multiple colicin producer can kill sensitive cells and those cells encoding only a single colicin type. It is predicted this outcome will occur when the costs associated with the production of two or more colicins by a cell is not too severe, and gene exchange among different producing strains is sufficiently frequent.

Although the data show there are multiple bacteriocins present in a population of E. coli (Riley \& Gordon, 1996; Gordon et al., 1998), there have been no systematic attempts to determine if the production of multiple bacteriocins by an E. coli strain is a common phenomenon or simply a theoretical possibility. Therefore, the primary goal of this study was to determine the frequency with which strains of E. coli produce multiple bacteriocins. Achieving this goal required integrating phenotypic and genotypic approaches, because there is no reliable phenotypic technique to determine if a strain produces a microcin, and phenotypic methods of colicin identification (Pugsley \& Oudega, 1987) cannot distinguish between a strain that produces an unknown colicin and one that produces multiple colicins.

\section{METHODS}

Strain collection. The E. coli strain collection examined for this study was that described by Gordon et al. (2005). The collection consists of 266 isolates collected from the faeces of people living in the city of Canberra and its surrounds (Australian Capital Territory, Australia). A single E. coli isolate was taken from each faecal sample and a single faecal sample was collected from each person. The method of Clermont et al. (2000) was used to assign the E. coli isolates to one of the four main genetic groups identified in the ECOR collection (Ochman \& Selander, 1984; Herzer et al., 1990). The groups are designated A, B1, B2 and D. The isolates had also been screened for the presence of 29 virulence factors associated with intestinal and extra-intestinal disease using a modification of the multiplex PCR protocol described by Johnson \& Stell (2000).

Phenotypic screening for colicin production. The frequency of colicin production was determined using the method described by Gordon et al. (1998). Briefly, each strain was grown in Luria broth overnight. A $1 \mathrm{ml}$ aliquot of the overnight culture was added to $10 \mathrm{ml}$ Luria broth and incubated for $1 \mathrm{~h}$; mitomycin $\mathrm{C}$ was then added and the culture incubated for a further $4 \mathrm{~h}$. A $1.5 \mathrm{ml}$ aliquot of the induced culture was transferred to a microfuge tube and then centrifuged for $5 \mathrm{~min}$ at $10000 \mathrm{~g}$, after which the supernatant was transferred to another microfuge tube containing $50 \mu \mathrm{l}$ chloroform. The sterile crude extract was stored at $5{ }^{\circ} \mathrm{C}$ until required. All incubations were carried out at $37^{\circ} \mathrm{C}$ with shaking at 150 r.p.m. Aliquots of the crude extract were then spotted onto Luria soft agar lawns of the E. coli K-12 strains BZB1011 and CSH50. This procedure was repeated three times for each strain.

Extracts that killed the sensitive K-12 cells could contain colicins or bacteriophage. To distinguish between the two, several assays were carried out: extracts were treated with trypsin (colicin degraded - phage unaffected), frozen at $-80{ }^{\circ} \mathrm{C}$ for 2 days (colicin unaffected phage inactivated) and filtered through an Amicon 100000 Da microconcentrator (colicins pass through filter - phage removed). Finally, crude extracts were serially diluted (twofold steps) and dilutions plated onto sensitive lawns: if the extract contains bacteriophage individual plaques will appear. Preliminary phenotypic identification of the colicin being produced by a strain was made by spotting the crude extract onto lawns each containing a K-12 strain that harboured a known colicin plasmid (Pugsley \& Oudega, 1987). If the colicin present in the extract is the same as that produced by the cells in the lawn, then these cells will not be killed, while if the colicin in the extract is different, then the cells in the lawn will be killed.

PCR-based screening for microcin production and bacteriocin identification. Over two dozen colicins have been characterized. In order to minimize the total amount of screening required, the results of the phenotypic identification of the colicins produced by this collection of strains were used to select the colicins to be screened for. The phenotypic results suggested that the colicins A, B, $\mathrm{D}, \mathrm{E} 1, \mathrm{E} 2, \mathrm{E} 6, \mathrm{E} 7, \mathrm{Ia}, \mathrm{Ib}, \mathrm{K}$ and $\mathrm{M}$ might be present in this collection of strains. PCR primers for these colicins were taken from the literature or developed using previously published sequence data. Nine microcins have been identified in E. coli (Braun et al., 2002; Gillor et al., 2004). PCR primers for eight of these microcins were developed from previously published sequences or taken from the literature. No sequence data were available for microcin D93. Preliminary PCR screening for the eight microcins using a subset of 100 strains representing each of the four ECOR groups was undertaken. No microcin 24-producing strain was detected and this microcin was not screened for further. Thus, the entire collection of strains was screened for the presence of seven microcins. A supplementary table with the nucleotide sequences of all primers used in this study is available with the online version of this paper.

Template DNA was prepared using DNAzol (Invitrogen) according to the manufacturer's protocol. Amplification was done in a $25 \mu \mathrm{l}$ reaction mixture containing $2 \mu \mathrm{l}$ template DNA, $4 \mathrm{mM} \mathrm{MgCl} 2$ and 0.5 units Platinum Taq in $1 \times$ reaction buffer $[67 \mathrm{mM}$ Tris $/ \mathrm{HCl}$ $(\mathrm{pH} 8 \cdot 8), 16 \cdot 6 \mathrm{mM}\left(\mathrm{NH}_{4}\right)_{2} \mathrm{SO}_{4}, 0 \cdot 45 \%$ Triton X-100, $0 \cdot 2 \mathrm{mg}$ gelatin $\mathrm{ml}^{-1}$ and $0 \cdot 2 \mathrm{mM}$ dNTPs] together with $3 \mathrm{ng}$ each primer. Amplification conditions were: 1 cycle at $95^{\circ} \mathrm{C}$ for $12 \mathrm{~min} ; 25$ cycles of $94^{\circ} \mathrm{C}, 30 \mathrm{~s} ; 55^{\circ} \mathrm{C}, 30 \mathrm{~s} ; 68^{\circ} \mathrm{C}, 3 \mathrm{~min}$; and 1 cycle at $72^{\circ} \mathrm{C}$ for $3 \mathrm{~min}$. Electrophoresis was carried out using $2 \%$ agarose gels. Gels were stained with ethidium bromide, visualized using an ultraviolet transilluminator, and photographed. Colicins A, E1, E2, E6 and Ia/Ib were screened for individually and only strains producing a colicin 
phenotype were screened. For strains yielding a product for the Ia/Ib primer pair, the identity of the colicin was determined phenotypically (Pugsley \& Oudega, 1987). Primers for colicins D and K were multiplexed and all 266 strains were screened. Colicin B and microcins C7, $\mathrm{H} 47$ and B17 primers were multiplexed in a single reaction, as were the primers for microcins M, L, J25 and colicin M, and all strains were screened for these eight bacteriocins. All strains had been previously screened for microcin V (Gordon et al., 2005). For each of the bacteriocins detected a subset of the PCR products was sequenced to confirm their identity.

\section{RESULTS}

Of the 266 strains screened, $38 \%$ produced at least one bacteriocin, $24 \%$ produced one or more colicins, and $20 \%$ produced one or more microcins. Mitomycin-inducible bacteriophages were detected in $7 \%$ of the strains. The frequencies of the various bacteriocins detected in this collection of strains ranged from $0 \%$ for colicins $\mathrm{A}, \mathrm{D}$ and E6 to $13 \%$ for microcin $\mathrm{H} 47$ (Table 1). Of the 102 bacteriocin-producing strains, $42 \%$ produced one type of bacteriocin, $41 \%$ produced two, $16 \%$ produced three, and one strain was found to produce four different bacteriocins (Table 2).

Several of the bacteriocins were found to co-occur in a strain significantly more often than would be expected by chance (Table 3). Microcins H47 and M almost always co-occurred in a strain; there was only one strain where $\mathrm{H} 47$ was detected in the absence of $\mathrm{M}$ and one strain where $\mathrm{M}$ occurred but not H47. Other positive associations were colicin Ia and microcin V, as well as colicins B and M. Colicin E1 was coassociated with colicin $\mathrm{M}$, but only if the strain did not also encode colicin B. A similar outcome was observed with the

Table 1. Frequency of bacteriocins in a collection of $E$. coli faecal isolates from humans

\begin{tabular}{|llc|}
\hline Bacteriocin class & Type & Frequency $(\%)(\boldsymbol{n}=\mathbf{2 6 6})$ \\
\hline Colicins & Ia & $9 \cdot 0$ \\
& E1 & $8 \cdot 3$ \\
M & $4 \cdot 5$ \\
E7 & $2 \cdot 3$ \\
K & $1 \cdot 9$ \\
E2 & $1 \cdot 1$ \\
B & $1 \cdot 1$ \\
Ib & $0 \cdot 3$ \\
E6 & 0 \\
A & 0 \\
D & 0 \\
H4 & $13 \cdot 2$ \\
M & $12 \cdot 0$ \\
V & $5 \cdot 3$ \\
& C7 & $1 \cdot 5$ \\
J25 & $1 \cdot 5$ \\
L & $1 \cdot 5$ \\
& B17 & $1 \cdot 1$ \\
& &
\end{tabular}

Table 2. Combinations of bacteriocins detected in a single $E$. coli strain from a collection of faecal isolates from humans

\begin{tabular}{|c|c|}
\hline Bacteriocin genotype of strain & Frequency $(\%)(n=102)$ \\
\hline$?^{*}$ & $4 \cdot 9$ \\
\hline $\mathrm{B} / \mathrm{cM}$ & $2 \cdot 9$ \\
\hline B17 & $2 \cdot 0$ \\
\hline $\mathrm{cM} \dagger$ & $4 \cdot 9$ \\
\hline $\mathrm{cM} / \mathrm{E} 1$ & $3 \cdot 9$ \\
\hline E1 & $6 \cdot 9$ \\
\hline $\mathrm{E} 1 / \mathrm{E} 2$ & $1 \cdot 0$ \\
\hline $\mathrm{E} 1 / \mathrm{K}$ & $1 \cdot 0$ \\
\hline E2 & $1 \cdot 0$ \\
\hline E7 & $3 \cdot 9$ \\
\hline $\mathrm{H} 47$ & $1 \cdot 0$ \\
\hline $\mathrm{H} 47 / \mathrm{L}$ & $1 \cdot 0$ \\
\hline $\mathrm{H} 47 / \mathrm{L} / \mathrm{E} 1$ & $1 \cdot 0$ \\
\hline $\mathrm{H} 47 / \mathrm{M}$ & $21 \cdot 6$ \\
\hline $\mathrm{H} 47 / \mathrm{M} / ?$ & $2 \cdot 0$ \\
\hline $\mathrm{H} 47 / \mathrm{M} / \mathrm{B} 17$ & $1 \cdot 0$ \\
\hline $\mathrm{H} 47 / \mathrm{M} / \mathrm{C} 7$ & $2 \cdot 0$ \\
\hline $\mathrm{H} 47 / \mathrm{M} / \mathrm{E} 1$ & $2 \cdot 0$ \\
\hline $\mathrm{H} 47 / \mathrm{M} / \mathrm{E} 7$ & $1 \cdot 0$ \\
\hline $\mathrm{H} 47 / \mathrm{M} / \mathrm{K}$ & $1 \cdot 0$ \\
\hline $\mathrm{H} 47 / \mathrm{V}$ & $1 \cdot 0$ \\
\hline Ia & $9 \cdot 8$ \\
\hline $\mathrm{Ia} / \mathrm{E} 1$ & $4 \cdot 9$ \\
\hline $\mathrm{Ia} / \mathrm{V}$ & $2 \cdot 0$ \\
\hline $\mathrm{Ia} / \mathrm{V} / \mathrm{C} 7$ & $1 \cdot 0$ \\
\hline $\mathrm{Ia} / \mathrm{V} / \mathrm{E} 1$ & $1 \cdot 0$ \\
\hline $\mathrm{Ia} / \mathrm{V} / \mathrm{E} 2 / \mathrm{E} 7$ & $1 \cdot 0$ \\
\hline $\mathrm{Ia} / \mathrm{V} / \mathrm{J} 25$ & $2 \cdot 9$ \\
\hline $\mathrm{Ia} / \mathrm{V} / \mathrm{K}$ & $1 \cdot 0$ \\
\hline $\mathrm{Ib} / \mathrm{V}$ & $1 \cdot 0$ \\
\hline J25 & $1 \cdot 0$ \\
\hline $\mathrm{K}$ & $2 \cdot 0$ \\
\hline $\mathrm{L}$ & $2 \cdot 0$ \\
\hline $\mathrm{M} / \mathrm{C} 7$ & $1 \cdot 0$ \\
\hline $\mathrm{V}$ & $2 \cdot 9$ \\
\hline
\end{tabular}

co-association of colicin E1 and colicin Ia: E1 was coassociated with Ia provided that microcin $\mathrm{V}$ was absent. Two significant three-way co-associations were observed (Table 3); microcin J25 was detected in strains where both Ia and $\mathrm{V}$ were present, but was not significantly coassociated with either bacteriocin when they occurred on their own. There was a weak, but significant, association between microcin C7 and microcins H47 and M.

The frequency of bacteriocin-producing strains did not vary with a strain's ECOR group membership (likelihood ratio test: $\chi^{2}=5 \cdot 70, \quad P=0 \cdot 127$ ) (Table 4$)$. However, strains producing more than one bacteriocin were more likely to 
Table 3. Significant co-associations of bacteriocins in $E$. coli strains isolated from humans

\begin{tabular}{|c|c|c|c|}
\hline Co-association & $\begin{array}{l}\text { Likelihood } \\
\text { ratio } \chi^{2}\end{array}$ & $P>\chi^{2}$ & $\boldsymbol{\kappa}^{*}$ \\
\hline Microcin $\mathrm{H} 47$ with microcin $\mathrm{M}$ & $157 \cdot 76$ & $<0 \cdot 0001$ & $0 \cdot 915$ \\
\hline Colicin Ia with microcin V & $29 \cdot 25$ & $<0 \cdot 0001$ & $0 \cdot 436$ \\
\hline Microcin J25 with Ia/V & $15 \cdot 67$ & $<0 \cdot 0001$ & $0 \cdot 415$ \\
\hline Colicin B with colicin M & $19 \cdot 38$ & $<0 \cdot 0001$ & $0 \cdot 389$ \\
\hline Colicin E1 with Ia & $6 \cdot 96$ & $=0 \cdot 0083$ & $0 \cdot 191$ \\
\hline Colicin M with E1 & $6 \cdot 54$ & $=0 \cdot 0106$ & $0 \cdot 188$ \\
\hline Microcin C7 with $\mathrm{H} 47 / \mathrm{M}$ & $5 \cdot 06$ & $=0 \cdot 0245$ & 0.099 \\
\hline
\end{tabular}

${ }^{\star}$ Kappa is an index quantifying the degree of co-association. $\kappa=\left[\left(O^{-}+O^{+}\right)-\left(E^{-}+E^{+}\right)\right] /\left(N-E^{-}+E^{+}\right)$, where $O^{-}$is the number of cases where both traits are absent in a strain and $\mathrm{O}^{+}$the number of cases where both are present. $E^{-}$and $E^{+}$are the expected number of cases where the traits are either both present or absent assuming the traits are randomly associating and $N$ is the total number of samples.

be members of group $\mathrm{B} 2$ and less likely to belong to groups A or D (likelihood ratio test: $\chi^{2}=24 \cdot 86, P<0 \cdot 001$ ) (Table 4). The probability of a strain harbouring the colicins E1 or Ia, or microcin $\mathrm{V}$, was independent of the strain's ECOR group membership (likelihood ratio test: colicin E1, $\chi^{2}=3 \cdot 74$, $P=0 \cdot 290 ;$ colicin Ia, $\chi^{2}=0.65, P=0.884 ;$ microcin V, $\chi^{2}=3.08, \quad P=0.379$ ), whilst the likelihood of a strain harbouring colicin $\mathrm{M}$ or the microcins $\mathrm{H} 47$ and $\mathrm{M}$ did depend on the strains' ECOR group membership (likelihood ratio test: colicin $\mathrm{M}, \chi^{2}=16 \cdot 54, P<0 \cdot 001$; microcin H47, $\chi^{2}=35 \cdot 13, \quad P<0.001 ;$ microcin $M, \chi^{2}=37 \cdot 83$, $P<0.001)$. More than $85 \%$ of the strains positive for microcins $\mathrm{H} 47$ and $\mathrm{M}$ were members of group B2, whilst $75 \%$ of the strains positive for colicin $\mathrm{M}$ were group $\mathrm{D}$ strains.

\section{DISCUSSION}

The phenotypic assay for mitomycin C-inducible bacteriocin production detects virtually all strains bearing a colicin gene (Riley \& Gordon, 1992; Gordon et al., 1998; this study). A significant exception to this outcome related to strains where only colicin $\mathrm{M}$ genes were detected. None of these strains produced a colicin phenotype. However, all strains were screened for this colicin. Consequently, it is unlikely that the frequency of colicin production in this collection of strains has been significantly underestimated. Furthermore, the colicins produced by $88 \%$ of the 60 strains yielding a mitomycin C-inducible killing phenotype were identified.

However, it is possible that the frequency of microcin production has been underestimated. There is no reliable phenotypic method for detecting microcin production. Furthermore, PCR-based screening techniques can only be used for those microcins that have been characterized. The inability to detect microcin phenotype reliably is likely the reason that far fewer microcins than colicins from $E$. coli have been characterized. Despite these limitations, the results of this survey suggest that among faecal isolates of E. coli, microcin production is as common as colicin production and that at least half of bacteriocinogenic E. coli strains produce more than one bacteriocin.

The co-associations of microcins $\mathrm{H} 47$ and $\mathrm{M}$ and colicins B and $M$ have been reported previously (Braun et al., 2002). However, the extent to which colicins B and M co-associate may be overestimated. None of the strains in which only microcin $\mathrm{M}$ was detected produced a mitomycin Cinducible phenotype, whilst all strains in which colicin B was detected did produce a killing phenotype. The other significant co-associations have not previously been reported and the nature of these associations is unknown. It is known that colicin Ia and microcin $\mathrm{V}$ are usually encoded on large conjugative plasmids, but it is not known whether, in strains encoding both Ia and V, the genes for both bacteriocins are on the same or separate plasmids. Further investigations are under way which aim to determine the nature of the colicin Ia and microcin V association as well as the other co-associations identified in this study.

Although the production of more than one bacteriocin by an E. coli strains is common, our data indicate that different bacteriocins do not co-associate at random. Of the combinations found to co-occur more frequently than expected by chance (Table 3), all have the characteristic that at least one of the co-occurring bacteriocins is secreted by the cell rather than released via cell lysis. There were only three examples of the apparent co-occurrence of colicins released via cell lysis: one strain positive for colicins E2 and E7, one encoding colicins E2 and E1, and one positive for

Table 4. Frequency of $E$. coli strains producing multiple bacteriocins with respect to their ECOR group membership (groups A, B1, B2, D)

\begin{tabular}{|lcccc|}
\hline \multirow{2}{*}{ Type of producer } & \multicolumn{4}{c|}{ Frequency (\%) } \\
\cline { 2 - 5 } & A $(\boldsymbol{n}=\mathbf{5 2})$ & B1 $(\boldsymbol{n}=\mathbf{3 3})$ & B2 $(\boldsymbol{n = 1 2 0})$ & D $(\boldsymbol{n}=\mathbf{6 1})$ \\
\hline No bacteriocin produced & $67 \cdot 3$ & $72 \cdot 7$ & $54 \cdot 2$ & $65 \cdot 6$ \\
One bacteriocin produced & $21 \cdot 2$ & $12 \cdot 1$ & $10 \cdot 8$ & $24 \cdot 6$ \\
Two or more bacteriocins produced & $11 \cdot 5$ & $15 \cdot 2$ & $35 \cdot 0$ & $9 \cdot 8$ \\
\hline
\end{tabular}


colicins E1 and K. However, the co-occurrence of colicins E2 and E7 may be a PCR artefact. At least two examples of E2 and E7 chimeras have been reported, which have resulted from recombination of portions of the E2 and E7 colicin operons in a single plasmid (Tan \& Riley 1997; Nandiwada et al., 2004).

When considering the dynamics of those colicins released via cell lysis, three cell populations need to be considered: colicin-producing, colicin-sensitive and colicin-resistant cells. Colicin resistance occurs when mutations eliminate or alter the receptor to which a particular colicin binds. Riley \& Gordon (1999) developed a conceptual model for the dynamics of colicin-producing, -resistant and -sensitive cell populations. The relative fitness of producer, sensitive and resistant cells has a structure analogous to the classic game of Rock, Paper, Scissors (Kerr et al., 2002). Producing cells outcompete sensitive cells due to the action of the colicin. Sensitive cells out-compete resistant cells, because resistant cells are at a growth rate disadvantage relative to sensitive cells as resistance usually reduces the ability of the cell to acquire an essential resource (Feldgarden \& Riley, 1999). Resistant cells out-compete producing cells for two reasons: resistant cells are unaffected by the colicin, and there is an inherent cost to colicin production that occurs as a consequence of cell lysis. Thus, colicin producers suffer a growth rate disadvantage relative to resistant cells that is not offset by the killing action of the colicin.

The results reveal that, in this population of E. coli, bacteriocins were detected 179 times and that $77 \%$ of these represented bacteriocins secreted by the cell rather than released due to cell lysis. Although there are no data, it is very likely that the cost of production is lower for those bacteriocins secreted from the cell compared to bacteriocins released via cell lysis (Dykes \& Hastings, 1997). If this is indeed the case, then one critical component of the Rock, Paper, Scissors scenario may not be valid for the secreted bacteriocins. That is, strains resistant to secreted bacteriocins may not experience a universal fitness advantage when in competition with strains producing a secreted bacteriocin. Although the resistant cells will be unaffected by the bacteriocin, the growth rate disadvantage that resistant cells suffer due to the loss or modification of an important surface receptor may be greater than the cost associated with producing a secreted bacteriocin. Further empirical evidence concerning the costs associated with producing a secreted bacteriocin is required.

The acquisition of multiple bacteriocins by a cell confers a selective advantage to the cell because such cells cannot only kill sensitive cells but any cells in the population that harbour only one of the bacteriocins. There may also be other benefits arising from multiple bacteriocin carriage. In naturally occurring $E$. coli populations, resistance to colicins is a common phenomenon and most cells are resistant to most co-occurring colicins (Riley \& Gordon, 1992; Gordon et al., 1998; Feldgarden \& Riley, 1999). In those strains harbouring multiple bacteriocins, many, although not all, of the combinations represent bacteriocins that exploit different surface receptors. For example, the colicins Ia and E1 exploit the receptors Cir and BtuB, respectively (Smarda \& Macholan, 2000; Braun et al., 2002). A mutation in one receptor is far more likely than the simultaneous occurrence of mutations in two different receptors. Thus, harbouring multiple bacteriocins exploiting different surface receptors may slow the evolution of resistance in populations where the dominant bacteriocinogenic strain produces multiple bacteriocins compared to populations where the dominant producer encodes a single bacteriocin. Microcins $\mathrm{H} 47$ and $\mathrm{M}$ are thought to exploit the same receptors (Cir, Fiu, IroN and FepA), whilst colicin Ia and microcin $\mathrm{V}$ are both thought to exploit the Cir receptor (Braun et al., 2002). The evolution of resistance may be slower or more costly, even for those co-associations where both bacteriocins exploit the same receptors, if the bacteriocins bind to different regions of the receptor (Smarda \& Macholan, 2000). Evolving simultaneous resistance to bacteriocins that target different parts of the same receptor may greatly increase the likelihood that receptor function is completely lost.

Microcin V production is induced when iron is limited. Although it is well established that iron is a limited resource in extra-intestinal body sites (Ratledge \& Dover, 2000), it is generally not considered to be limiting in the lower intestinal tract of vertebrates. By contrast, colicin Ia is induced under conditions of general nutrient limitation, a state that does occurs in the lower intestinal tract. The ability to acquire iron when attempting to establish in extraintestinal body sites is considered to be an important virulence trait in E. coli (Ratledge \& Dover, 2000). The strains responsible for an extra-intestinal infection are thought to originate from the E. coli community residing in the infected individual's intestinal tract (Mobley \& Warren, 1996). Therefore, strains causing extra-intestinal infections must have a suite of traits that enable them to invade and establish in extra-intestinal body sites as well as traits that allow them to persist in the intestine. Thus, we conjecture that the joint carriage of an SOS-induced colicin (Ia) and an iron-induced microcin $(\mathrm{V})$ each confers a fitness advantage to the strain but in different environments: colicin Ia in the gut and microcin $\mathrm{V}$ in extra-intestinal body sites.

There is an intimate link between microcins and iron. Many microcins are induced under conditions of iron limitation and many exploit receptors on sensitive cells that are involved in iron acquisition: Cir, FepA, FhuA, FyuA and IroN. As previously stated, iron is an essential resource that is often in limited supply when E. coli is attempting to establish a population in an extra-intestinal body site. All strains encoding a microcin also carried one or more genes involved in iron acquisition: fyuA, iroN, iutA, ireA (Gordon et al., 2005; this study). By contrast, only $60 \%$ of the strains in which no microcins were detected encoded one or more of these iron-associated genes (likelihood ratio test: $\left.\chi^{2}=37 \cdot 33, \quad P<0 \cdot 0001\right)$. It may be that microcins are 
primarily involved in competition for iron. In iron-limited environments, sensitive cells competing with a microcinproducing population of cells will be at a disadvantage due to the action of the microcin. If resistance evolves in the sensitive cell population, this resistance will most often be due to the loss or modification of a receptor involved in iron uptake. Whilst the microcin will no longer be effective, the resistant strain may still be at a fitness disadvantage relative to the microcin producer as it may be less efficient at acquiring iron as compared to the microcin-producing strain that always has some sort of iron-acquisition system.

The results of this study showed that, in this population of $E$. coli, the bacteriocins that are actively exported from a cell are significantly more common than those released as a result of cell lysis. Much of our understanding of the ecological role and dynamics of bacteriocin production is restricted to those colicins released via cell lysis. Given that the dynamics of the exported bacteriocins may be quite different, additional mathematical theory and empirical studies are needed if we are to understand the role that these bacteriocins play in natural populations. This study has also demonstrated that the majority of bacteriocin-producing E. coli strains produce more than one bacteriocin and that the bacteriocins that are significantly co-associated in a strain are not a random subset of the bacteriocins present in the population. Experiments are now being undertaken to determine why colicins released via cell lysis seldom co-occur in a cell and to understand the nature of the fitness advantage accruing to cells that produce multiple bacteriocins.

\section{ACKNOWLEDGEMENTS}

The technical assistance of Joanne Alison and Jane Littlefield-Wyer was invaluable. The Australian Research Council funded this study.

\section{REFERENCES}

Braun, V., Patzer, S. I. \& Hantke, K. (2002). Ton-dependent colicins and microcins: modular design and evolution. Biochimie 84, 365-380.

Center for Veterinary Medicine (1997). CVM Policy on Competitive Exclusion. FDA Center for Veterinary Medicine. http:://www.fda.gov/ $\mathrm{cvm} /$ index/updates/complexcl.html

Chao, L. \& Levin, B. R. (1981). Structured habitats and the evolution of anticompetitor toxins in bacteria. Proc Natl Acad Sci U S A 78, 6324-6328.

Clermont, O., Bonacorsi, S. \& Bingen, E. (2000). Rapid and simple determination of Escherichia coli phylogenetic group. Appl Environ Microbiol 66, 4555-4558.

Czaran, T. L., Hoekstra, R. F. \& Pagie, L. (2002). Chemical warfare between microbes promotes biodiversity. Proc Natl Acad Sci U S A 99, 786-790.

Durrett, R. \& Levin, S. (1997). Allelopathy in spatially distributed populations. J Theor Biol 185, 165-171.

Dykes, G. A. \& Hastings, J. W. (1997). Selection and fitness in bacteriocin producing bacteria. Proc $R$ Soc Lond B 264, 683-687.
Feldgarden, M. \& Riley, M. A. (1999). The phenotypic and fitness effects of colicin resistance in Escherichia coli K12. Evolution 53, 1019-1027.

Frank, S. A. (1994). Spatial polymorphism of bacteriocins and other allelopathic traits. Evol Ecol 8, 369-386.

Gillor, O., Kirkup, B. C. \& Riley, M. A. (2004). Colicins and microcins: the next generation antimicrobials. Adv Appl Microbiol 54, 129-146.

Gordon, D. M. \& Riley, M. A. (1999). A theoretical and empirical investigation of the invasion dynamics of colicinogeny. Microbiology 145, 655-661.

Gordon, D. M., Riley, M. A. \& Pinou, T. (1998). Temporal changes in the frequency of colicinogeny in $E$. coli from house mice. Microbiology 144, 2233-2240.

Gordon, D. M., Stern, S. E. \& Collignon, P. J. (2005). The influence of the age and sex of human hosts on the distribution of Escherichia coli ECOR groups and virulence traits. Microbiology 151, 15-23.

Herzer, P. J., Inouye, S., Inouye, M. \& Whittam, T. S. (1990). Phylogenetic distribution of branched RNA-linked multicopy singlestranded DNA among natural isolates of Escherichia coli. J Bacteriol 172, 6175-6181.

Johnson, J. R. \& Stell, A. L. (2000). Extended virulence genotypes of Escherichia coli strains from patients with urosepsis in relation to phylogeny and host compromise. J Infect Dis 181, 261-272.

Kerr, B., Riley, M. A., Feldman, M. W. \& Bohannan, B. J. (2002). Local dispersal promotes biodiversity in a real-life game of rock-paperscissors. Nature 418, 171-174.

Kirkup, B. C. \& Riley, M. A. (2004). Antibiotic-mediated antagonism leads to a bacterial game of rock-paper-scissors in vivo. Nature $\mathbf{4 2 8}$, 412-414.

Levin, B. R. (1988). Frequency-dependent selection in bacterial populations. Philos Trans R Soc Lond B 319, 459-472.

Mobley, H. L. T. \& Warren, J. W. (1996). Molecular pathogenesis and clinical management. Urin Tract Infect 3, 67-94.

Nandiwada, L. S., Schamberger, G. P., Schafer, H. W. \& Diez-Gonzalez, F. (2004). Characterization of an E2-type colicin and its application to treat alfalfa seeds to reduce Escherichia coli O157: H7. Int J Food Microbiol 93, 267-279.

Ochman, H. \& Selander, R. K. (1984). Standard reference strains of Escherichia coli from natural populations. J Bacteriol 157, 690-693.

Pugsley, A. P. \& Oudega, B. (1987). Methods of studying colicins and their plasmids. In Plasmids, a Practical Approach, pp. 105-161. Edited by K. G. Hardy. Oxford: IRL Press.

Ratledge, C. \& Dover, L. G. (2000). Iron metabolism in pathogenic bacteria. Annu Rev Microbiol 54, 881-941.

Riley, M. A. \& Gordon, D. M. (1992). A survey of Col plasmids in natural isolates of Escherchia coli and an investigation into the stability of Col plasmid lineages. J Gen Microbiol 138, 1345-1352.

Riley, M. A. \& Gordon, D. M. (1996). The ecology and evolution of bacteriocins. J Ind Microbiol 17, 151-158.

Riley, M. A. \& Gordon, D. M. (1999). A model of intraspecific microbial warfare. Trends Microbiol 7, 129-133.

Riley, M. A. \& Wertz, J. E. (2002). Bacteriocins: evolution, ecology, and application. Annu Rev Microbiol 56, 117-137.

Smarda, J. \& Macholan, L. (2000). Binding domains of colicins E1, E2 and E3 in the receptor protein BtuB of Escherichia coli. Folia Microbiol 45, 379-385.

Tan, Y. \& Riley, M. A. (1997). Nucleotide polymorphism in colicin E2 gene clusters: evidence for nonneutral evolution. Mol Biol Evol 14, $666-673$. 